\title{
WestVirginiaUniversity
}

THE RESEARCH REPOSITORY @ WVU

Graduate Theses, Dissertations, and Problem Reports

2006

\section{The effects of social bond and neutralization on juvenile drug usage}

Adam Shields

West Virginia University

Follow this and additional works at: https://researchrepository.wvu.edu/etd

\section{Recommended Citation}

Shields, Adam, "The effects of social bond and neutralization on juvenile drug usage" (2006). Graduate Theses, Dissertations, and Problem Reports. 835.

https://researchrepository.wvu.edu/etd/835

This Thesis is protected by copyright and/or related rights. It has been brought to you by the The Research Repository @ WVU with permission from the rights-holder(s). You are free to use this Thesis in any way that is permitted by the copyright and related rights legislation that applies to your use. For other uses you must obtain permission from the rights-holder(s) directly, unless additional rights are indicated by a Creative Commons license in the record and/ or on the work itself. This Thesis has been accepted for inclusion in WVU Graduate Theses, Dissertations, and Problem Reports collection by an authorized administrator of The Research Repository @ WVU. For more information, please contact researchrepository@mail.wvu.edu. 
The Effects of Social Bond and Neutralization on Juvenile Drug Usage

by

Adam Shields

Thesis submitted to the Eberly College of Arts and Sciences

At West Virginia University

in partial fulfillment of the requirements

for the degree of

\author{
Master of Arts \\ in \\ Sociology
}

Approved by

James J. Nolan III, Ph.D., Committee Chairperson

Ronald Althouse, Ph.D

Patricia Rice, M.A.

Division of Sociology and Anthropology

Morgantown, West Virginia

2006

Keywords: Social Control, Neutralization, Juvenile Delinquency

Copyright 2006 Adam Shields 


\section{Abstract \\ The Effects of Social Bond and Neutralization on Juvenile Drug Usage By Adam Shields}

The purpose of this study is to examine the effects of social bond and neutralization on juvenile drug usage. Part I of the Evaluation of the Gang Resistance Education and Training (G.R.E.A.T.) Program in the United States (1995-1999) was used for the data analysis. When controlling for other variables, the data revealed that juveniles who accept neutralization of stealing and juveniles who are involved with other delinquent peers are more likely to use illegal drugs. In addition, the data revealed that an adolescent's gender was significant in determining drug usage. The results generally support Hirschi's (1969) Social Bond Theory, and suggest that juveniles with a weakened bond to society are more likely to get involved with drugs. The results generally support Sykes and Matzas' (1957) Theory of Neutralization, and suggest that juveniles who accept neutralization are likely to get involved with drugs. 


\section{Dedication}

I would like to dedicate this work to my parents, Bruce and Robin Shields, and my

friends. 


\section{Table of Contents}

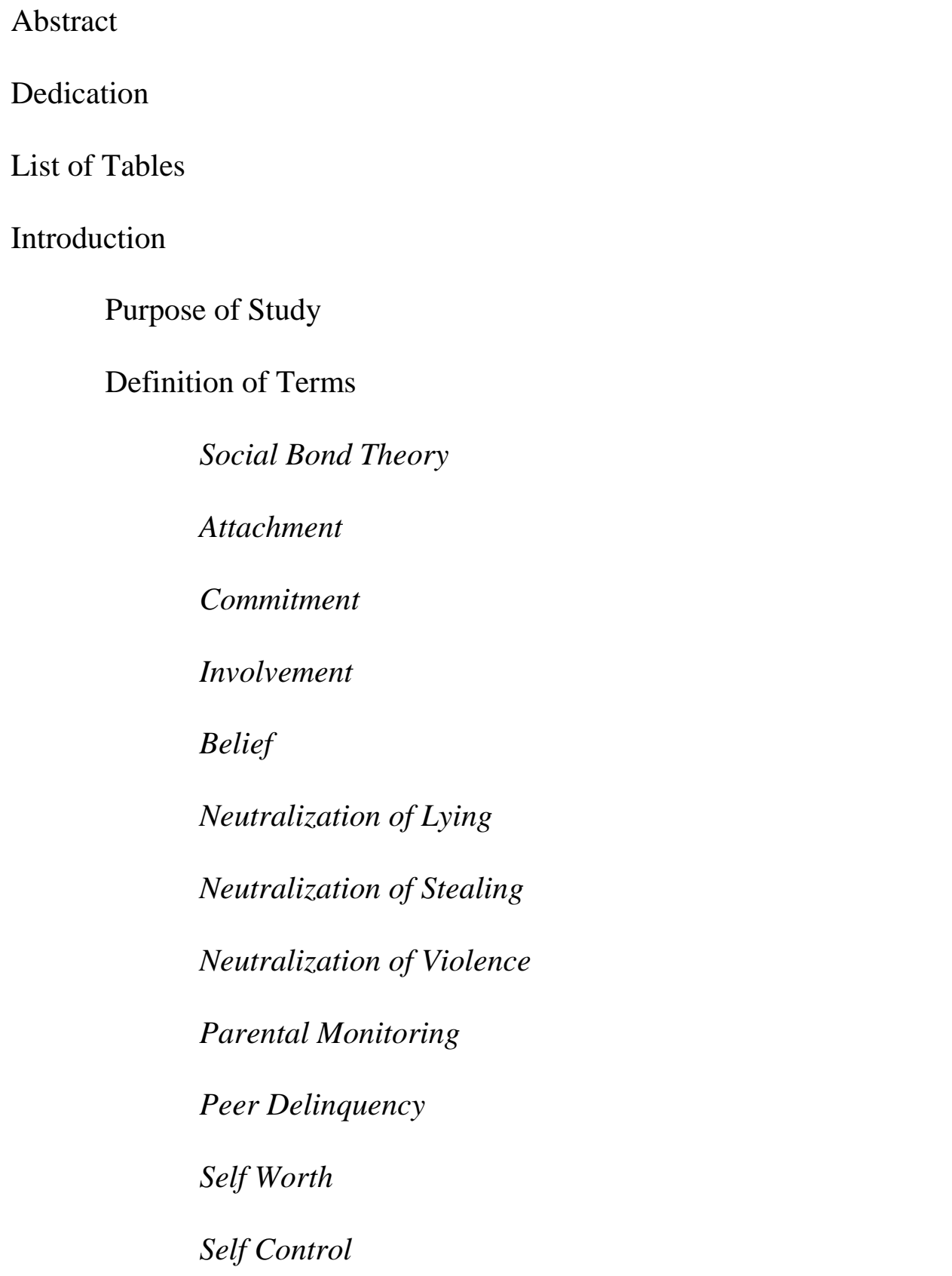

Delimitations and Limitations $\quad 6$

$\begin{array}{ll}\text { Significance of Study } & 7\end{array}$

Review of Literature $\quad 8$

$\begin{array}{ll}\text { Introduction } & 8\end{array}$ 
Test of Social Control and Delinquency 11

Test of Neutralization and Delinquency 13

$\begin{array}{ll}\text { Self Control and Delinquency } & 16\end{array}$

$\begin{array}{ll}\text { Parental Monitoring and Delinquency } & 17\end{array}$

$\begin{array}{ll}\text { Peer Delinquency and Association } & 19\end{array}$

$\begin{array}{ll}\text { Self Worth } & 21\end{array}$

$\begin{array}{ll}\text { Conclusion } & 23\end{array}$

$\begin{array}{ll}\text { Methods } & 23\end{array}$

$\begin{array}{ll}\text { Data } & 23\end{array}$

$\begin{array}{ll}\text { Sample } & 24\end{array}$

$\begin{array}{ll}\text { Study Design } & 24\end{array}$

$\begin{array}{ll}\text { Measures } & 25\end{array}$

Independent Variables $\quad 25$

Demographic Variables $\quad 25$

$\begin{array}{ll}\text { Social Bond } & 26\end{array}$

$\begin{array}{ll}\text { Neutralization } & 27\end{array}$

Dependent Variables $\quad 30$

$\begin{array}{ll}\text { Data analysis } & 31\end{array}$

$\begin{array}{ll}\text { Hypothesis } & 31\end{array}$

Hypothesis 1

Hypothesis 2

$\begin{array}{ll}\text { Findings } & 32\end{array}$

Bivariate logistic regression 32 
Multivariate logistic regression

Examining hypothesis 1

Examining Hypothesis 2

Discussion and Conclusion

References 


\section{List of Tables}

1. Demographic Variables 30

2. Tables of Indexes 31

3. Bivariate Logistic Regression to Predict Juvenile Drug Usage 32

4. Multivariate Logistic Regression for Juvenile Drug usage 34 


\section{Introduction}

How does a person’s social bond affect their choice to use illegal drugs? Does neutralization of lying, stealing, and violence affect a person's choice to use illegal drugs? What about demographic characteristics, mixed with a person’s social bond and ideas of neutralization affect their idea of using illegal drugs? These questions about juvenile delinquency have been important topics for criminologists and sociologists for many years. Sykes and Matza’s (1957) “Theory of Neutralization and Hirschi’s (1969) “Social Bond Theory” have been used by many researchers to explain such phenomena as juvenile delinquency.

In today’s society people tend to recognize two kinds of drugs, legal and illegal. Caffeine, nicotine, and over-the-counter medications (i.e. Tylenol, Aleve, or Robitussin) fit into the category of legal drugs, while popular illegal drugs are marijuana, crackcocaine, and heroin. Unfortunately, drugs--both legal and illegal--have become more accessible to the youths of today. Some researchers have found that teenagers, along with adults, have developed ways to abuse the over-the-counter medications to achieve a euphoric state of mind; “drugs are being used because of social pressure and personal pleasure” (Teevan and Dryburgh 1999: 78). It has been noted by researchers that substance abuse follows a predictable progression, beginning with alcohol and cigarettes, and then on to marijuana, followed by cocaine, hallucinogens, and opiates (Young, Longstaffe, and Tenenbein 1999: 374). The likelihood of substance abuse may increase with the presence of several risk factors, including attitudes, personality, behavior, social and environmental influences, and biological or genetic factors (Young, Longstaffe, and Tenenbein 1999: 374). 
There are biological and social consequences to drug abuse. Some biological consequences to using drugs are death, organ damage, or bodily harm. While under the influence of an illegal drug, a person may not realize his or her tolerance; therefore, he or she may continuously take more of the drug until the body shuts down. Another biological consequence to drug usages is organ damage. While attempting to achieve an altered state of consciousness, or euphoric state of mind, a person may cause his or her heart, lungs or even brain to shut down or work improperly. Bodily harm can be caused in many different ways. While under the influence of a mind-altering substance, a person might not realize what he or she is doing. During the altered consciousness, peer influence may cause a person to partake in rituals of cutting him or her self with a sharp object, running into a street sign, or possibly playing in traffic, which may lead to scars and other noticeable marks on the body.

The use of illegal drugs can carry social consequences along with it. The social consequences may include anti-social behavior, violent out-breaks, or labeling. The influence of illegal drugs may cause a person to break away from society. By breaking away, he or she can cause a weakening of the social bonds that have been created over time. Another issue with drug use and abuse can be violent out-breaks. Tempers might flare up when a person is under the influence of an illegal drug, because their mindset has been altered. Having an altered mind set may cause a person to become violent and take his or her anger out on innocent family, friends or a loved-one.

Hirschi (1969) developed “social bond theory,” and concluded, “Persons will engage in delinquent behavior when their 'social bond' to society is weakened” (Alston and Harley 1995:32). The theory was used to explain why some juveniles get involved 
with illegal drugs and why others don't get involved with them. His concept of social bond consisted of four key elements: attachment, commitment, involvement, and belief (Alston and Harley 1995:32). Attachment can be defined as having a close relationship with a parent, guardian, or loved one; commitment may be define as giving up time for sports, religious activities, or school activities. Involvement can be defined as being involved with extracurricular activities or groups and clubs; finally, belief can be defined as having a strong feeling for someone or something that is felt to be good.

Related but somewhat different, Sykes and Matza’s (1957) concept of neutralization that states a person who commits a deviant or criminal act tries to justify or rationalize his or her motives for committing such acts. However, their theory has come under some debate as to whether the justification and rationalization of the delinquency may also "precede deviant behavior and make deviant behavior possible” (Sykes 1957:666). How does this relate conceptually to social bond theory? It provides an explanation for those individuals, who are attached, committed, involved or have a belief of contemporary society but still engage in deviant acts. In other words a typically "good kid” may experiment in some delinquent acts and escape from theses bonds

During the late 1980s and throughout the 1990s the United States government employed a heavy emphasis on gang research and drug usage. Granted, there have been other studies that have helped explain the connection between gangs and drug usage and many studies have been born from the works of Hirschi (1969), Sykes, and Matza (1957). One particular study that was launched in the fall of 1994 was known as the Gang Resistant Education and Training study (G.R.E.A.T.). Eleven cities were picked to participate in a training class that was to deter adolescents from joining and participating 
in gangs. The following year, the study was administered to those students who participated in the class the prior year. G.R.E.A.T. consists of five distinct parts, (1) a cross sectional study of students, (2) parents, (3) teachers and administrators, (4) police officers, and (5) longitudinal study of students. The study was then used to determine if the training class was actually deterring students from entering into gang activity. Purpose of Study

The purpose of this study is to see how Hirschi’s (1969) "Social Bond Theory” and Sykes and Matzas’ (1957) “Theory of Neutralization” can help explain an adolescent's use of illegal drugs. From the G.R.E.A.T. data set, other control variables will be used such as parental monitoring, peer delinquency, and self-worth, to tie together the two theories and what their effects are on juvenile drug usage. A final goal is to see how age, sex, and ethnicity play a role in whether or not a person gets involved with drugs.

\section{Definition of Terms}

Social Bond Theory. Social bondtheory states, "it is the assumption that persons will engage in delinquent behavior when their 'social bond' to society is weakened" (Alston and Harley 1995: 32). The social bonds consist of a person’s attachment, commitment, involvement, and beliefs.

Attachment. Attachment corresponds to the affective ties that a youth forms to significant others (Alston and Harley 1995; Wiatrowski, Griswold, and Roberts 1981:525). For instance, attachment refers to a person’s attitude towards their parents, friends, teachers and ethic groups. 
Commitment. Commitment is related to the aspiration of going to college and attaining a high status job (Alston and Harley 1995; Wiatrowski, Griswold, and Roberts 1981:525). Commitment is a person's feelings toward grades, school, and other activities.

Involvement. Involvement refers to participation in conventional activities that lead toward socially valued success and status objectives (Alston and Harley 1995; Wiatrowski, Griswold, and Roberts 1981:525). The involvement can be a person’s time spent playing sports, going to church, volunteering, or doing nothing at all with his or her time.

Belief. Belief is an acceptance of the moral validity of a central social value system (Alston and Harley 1995; Wiatrowski, Griswold, and Roberts 1981:525). Belief refers to not just a religious belief, but an attitude toward police officers being nice or the importance of getting one's homework done.

Neutralization Theory. Neutralization theory refers to when a delinquent act has occurred; however the person justifies or excuses his or her actions as not being delinquent. Neutralization theory has five types that are considered justifications for delinquent behavior: the denial of responsibility, the denial of injury, the denial of the victim, the condemnation of the condemners, and the appeal to high loyalties (Sykes, Matza 1957:667-669).

Neutralization of lying. This refers to the level at which a person accepts and justifies lying in certain situations.

Neutralization of stealing. Neutralization of stealing refers to a person's acceptance and rationale of stealing in certain situations. 
Neutralization of violence. Neutralization of violence refers to a person's justification and rationale of using violence in certain situations.

Parental Monitoring. Parental monitoring refers to how much a parent watches over his or her son or daughter. For the study, it refers to the level at which children let their parents know where they are, how to contact them, and what friends they are with.

Peer Delinquency. "The concept of peer delinquency has been found to be important in studies of delinquency” (Akers, Krohn, Lanza-Kaduce and Radosevich 1979). Peer delinquency, for this study, refers to the level of deviant acts a child attributes to their peers and friends.

Self Worth. Self worth refers to how children feel about themselves. For instance, whether a child feels he or she is a useful person, a person of worth or just being good at being who he or she is as a person. It also refers to whether the child feels he or she can do things, feel good about him or her self, and when something is done, then it is done well.

Self Control. Self-control refers to how well a person can control his or her acts of deviance. "Individuals with low self-control are impulsive, prefer simple tasks, have a high risk-seeking potential, favor physical (as opposed to mental) activities, are self centered, and, finally, possess volatile tempers,” (Arneklev, Grasmick, and Bursik 1999:309).

\section{Delimitations and Limitations}

Initially, the study will be confined to one particular aspect of the G.R.E.A.T. data set, part I, which is a cross-sectional study. Therefore this study did not analyze the data in a longitudinal fashion. It examines social bonding (attachment, commitment, 
involvement and belief) and neutralization of lying, stealing, and violence to see how they affect a juvenile’s decision to use any form of illegal drugs. The data for this study came from part I, spring 1995 results from the surveys administered to all eighth-grade students ranging in age from 13-15 years old. The students had completed the G.R.E.A.T. program the prior academic year. The students surveyed were from 42 different schools in 11 different cities through out the United States.

Unfortunately, with this sample there are some limits to my research. First, the population chosen is random sample like, and strong generalizations cannot be made relative to the adolescent population as a whole (Esbensen and Osgood 1999:201). Next, the survey excluded private school students, students who are home schooled, or who was truant, sick, or absent that particular day. There is also a limit to the potential of under- representing “high-risk” youths (Esbesen and Osgood 1999: 201). In addition, since only 13-15 year old students were surveyed they might not represent the entire adolescent population.

Neutralization is a concept used to look at juvenile drug usage; however, in the data no variables made up a neutralization of drugs. Therefore as a proxy, this study was forced to use only the following forms of neutralization: neutralization of lying, stealing and violence.

\section{Significance of Study}

The significance of this study lies in adding its findings to future research in the areas of social control and neutralization with juvenile drug usage in several ways. First, the study will show how social bond theory and neutralization theory affect a juvenile's choice to use drugs. Second, the study will show how other variables such as parental 
monitoring, peer delinquency, self-control, and self-worth affect juvenile drug usage. Finally, the study will help to show the effectiveness of the G.R.E.A.T. program.

\section{Review of Literature}

\section{Introduction}

Drug abuse has been an issue in the media for many decades; however, the rate of juvenile drug usage has increased 44\% from 1989 to 1998 (Terry-McElrath and McBride 2004:62). "Substance abuse follows a predictable progression, beginning with alcohol and cigarettes, then on to marijuana, followed by cocaine, hallucinogens and opiates” (Young, Longstaffe, and Tenenbein 1999:374). Today, teenagers are finding all sorts of ways to “achieve a euphoric state,” (Young, Longstaffe, and Tenenbein 1999:372). Whether it is from inhaling toxic chemicals, smoking a joint, or even injecting heroin into their bodies, children today have become more involved in drugs than 20 years ago. What has caused this increase? With technology changing, drugs have become easier to transport and distribute to the youths of America. When a child is in junior high and even high school, both parent and peer influences have been found to be important variables in teenage drug and drinking behavior (Akers, Krohn, Lanza-Kaduce, and Radosevich 1979: 639). To 'fit in,' a teenager might buy trendy clothes, carry the latest MP3 player, drink, or do drugs.

What can lead a teenager down the path of drug abuse and which ones lead to non-use? Sykes and Matza (1957) introduce a theory for delinquency that uses the concept of neutralization to explain how some individuals drift from legal to illegal behaviors through means of justifications and excuses. Building off of Sutherland's 
differential association theory, Sykes and Matza found that juveniles who are caught committing crimes try to justify and rationalize their actions. "In this sense, the delinquent both has his cake and eats it too, for he remains committed to the dominant normative and yet so qualifies its imperatives that violations are 'acceptable' if not 'right’” (Sykes and Matza 1957: 667).

Hirschi (1969) explained juvenile delinquency by saying it was linked to a social bond with family, friends, and peers. Hirschi claimed "delinquent acts result when an individual's bond to society is weak or broken” (Greenberg 1999: 67; Alston and Debra 1995: 32). This means that when a person, young or old, was not able to connect with society in any way, they were more likely to become involved with criminal acts. Four categories were used to explain a person's social bond: attachment, commitment, involvement, and belief. By this Hirschi meant a person's attachment to family, friends, teachers, his or her commitment to extracurricular activities and schoolwork, a person's involvement with sports, church groups, and work, and his or her belief in religion or that certain items are good. These four ideas were the theoretical underpinning of Hirschi's social control theory.

Nearly 20 years later, Hirschi along with Gottfredson collaborated to create a new theory to explain juvenile delinquency that is called "The General Theory of Crime." The theory encompassed Hirschi's previous idea on delinquency, but added a new element, self-control. Gottfredson and Hirschi posit that both imprudent and criminal behaviors can be predicted by a common characteristic: lack of self-control (Katz 1999: 1). With the combination of the two theories, a prediction can be made that a person with 
a weakened or broken social bond and low self-control is more likely to engage in criminal acts.

In the 1950s, the entertainment industry helped propel the concept of the "perfect family” as a stay-at-home-mom to take care of the kids while dad was at work.

Unfortunately, in the modern world some families need both parents to work just to pay bills. "Theory suggests that children who are raised in homes where one or both of their biological parents are missing are significantly more likely to become involved in delinquency” (Kierkus and Baer 2002: 426). The concept of families has changed over the years; today there are more single-parent households with children, divorced parents raising blended families, and gay and lesbian couples adopting children than ever before. This fact could be a force in deterring delinquent acts among children, thus disproving Keirkus and Baer (2002) theory of needing the biological parents around to avoid delinquent behaviors. If children have both parents working, they can get away with whatever they want. Or can they? Thomas, Farrell, and Barnes (1996: 885) examined the impact of single-mother families and non-resident fathers on adolescent delinquency, heavy drinking, and illicit drug use. They found negative outcomes among white males single-mother households to be more involved with delinquent behavior than AfricanAmerican. With no watchful eye or hand to guide them, who is to say what teenagers may get into and what effects can come from their decisions.

A popular notion is that teenagers want to spend time with their friends and follow the crowd, so their peers become a big influence on their actions. Abbott (1998) found that gang members appeared to offend more than non-gang members with delinquent friends, suggesting an additional effect of gang membership over and above 
the delinquent peer effect” (Weerman and Smeenk 2005: 501). From the perspective of social bond theory, Deschenes (1990) found a significant gender variation in prevalence and frequency rates of delinquency and drug use. He concluded that females had a stronger social bond to the family, therefore deterring them from delinquent acts (Deschenes and Esbensen 1999: 65). It seems from the research that gangs may be an important influence on a teenager's behavior. Gang members may be persuasive toward new members, talking them into stealing, lying to their families, and even taking illegal drugs

One final reason teenagers might get involved with drugs is simple: the way they think about themselves, "the link between the self-concept and various social problems has commanded an important place in social theory and popular discourse” (Owens 1994: 391). It is believed that an adolescent with a higher self-esteem will behave in more socially acceptable ways than an adolescent with a lower self-esteem (Owens 1994: 391).

\section{Test of Social Bond Theory and Delinquency}

A better way to explain delinquent behavior was developed by Hirschi (1969), who thought that people who engage in delinquent acts tended to have lower social bonds. Until the middle part of the $20^{\text {th }}$ century, some people could not explain why children acted outside the values and norms of society. According to Wiatrowski, Griswold, and Roberts (1981: 527), the causes were primarily psychological: “individuals lacking a psychological sense of responsibility would, in theory, be free to behave without any notion of psychological accountability for their behavior.” However, even if it were psychological, Hirschi (1969) thought there was an underlying factor causing it, and that factor was social. 
According to social bond theory, every individual has unfulfilled needs and desires for fun and excitement. If time permitted everyone would pursue his or her own desires (Reginald and Harley 1995: 33). To sum up Hirschi’s idea, a person will be considered delinquent if any one or any combination of those elements had a weakened bond with society and "the stronger each element of the social bond, the less likely delinquent behavior will occur” (Wiatrowski, Griswold, and Roberts 1981; 525).

What can cause a person to have a weak bond with society? An issue with “parents, teachers, law enforcement officials and policy makers, and other adults have become increasingly concerned with how young people spend their time when they are not in school” (Huebner and Betts 2002: 123-124). Why are people concerned about this issue? Because, “adolescents spend about 6 to 7 hours a day in a formal school setting, leaving a large amount of free time available for other activities. Adolescents who are not involved in the community could lead down a path of delinquency, even if given an opportunity” (Huebner and Betts 2002: 123).

Shover, Norland, James, and Thorton (1979) studied the impact of gender on delinquency. They found that "through the effects of others, the masculine gender role has afforded males greater opportunity to engage in crime and simultaneously, has imposed fewer social controls on them...the feminine role ensures that they are more closely controlled by their parents and others (P. 163). Growing up, boys are taught to be independent and to act tough, thus allowing them to engage in more deviant acts because they have a low or weakened attachment to their parents. On the other hand, girls are taught to have a strong attachment to their parents, therefore, granting them less variability in their behavior. This finding by Shover, Norland, James, and Thorton 
supports the social bond theory in that because females have more of an attachment to their parents, they will be less deviant.

Forty years after it was introduced, Hirchi's theory continues to explain why some juveniles become delinquent and engage in illegal activities. A lack of attachment to conventional, law abiding citizens (such as parents, teachers, and police officers), no commitments to conventional goals or roles, no involvement in pro-social activities, or no belief in social norms or institutions may cause a weakened bond to society; therefore, a person may break away from the norm. Unfortunately, there is no way to stop this event from happening; however, help from parents, teachers, youth organization, police officers, and the community could help to deter an adolescent from leading a life of delinquency.

\section{Test of Neutralization Theory and Delinquency}

"In attempting to uncover the roots of juvenile delinquency, the social scientist has long since ceased to search for devils in the mind or stigma of the body” (Sykes and Matza 1957: 664). However, most scientists have come to realize that delinquency is learned and not inherited. Neutralization is one of the most widely known and frequently cited theories in criminology (Minor 1984: 995). Sutherland (1939) introduced "differential association theory" that stated criminal or delinquent behavior involves the learning of (a) techniques of committing crimes and (b) motives, drives, rationalizations, and attitudes favorable to the violation of law (Sykes and Matza 1957: 664). When a person is attached to and involved with other delinquent peers or is around delinquent adults, that person might learn that it is okay to live in a delinquent manner. Minor (1984: 1015) found that a persons involvement with delinquency could cause a loss of 
his or her values and morals. Therefore, the more excuses a person accepts for morally problematic behavior, the more likely he or she will approve of that behavior in the future.

Prior to Hirschi's introduction of “social bond theory,” a different but related theory was proposed. Sykes and Matza (1957) introduced their own theory of delinquency, which explained the concept of "neutralization." Simply stated, "the delinquent both has his cake and eats it too, for he remains committed to the dominant system and yet justifies that violations are 'acceptable' if not 'right'” (Sykes and Matza 1957: 667). This means that a criminal not only justifies his or her actions, but also gives rationale behind it. "The rationalization of delinquency is functional for deviants, as a device to reduce guilt resulting from deviant acts,” (Mitchell and Dodder 1990: 478).

There are five distinct categories within neutralization theory; (1) the denial of responsibility, (b) the denial of injury, (c) the denial of the victim, (d) the condemnation of the condemners, and (e) appeal to a higher loyalty (Sykes and Matza 1957: 667). First, the denial of responsibility proposed that he or she was considered the victim, pushed in a circumstance where there was no choice (Sykes and Matza 1957). Second, the denial of injury proposed that the offender did not harm anyone or that the victim was capable of replacing the stolen items (Sykes and Matza 1957). Third, the denial of the victim proposed that the offender defined the act is being wrong; the victim deserved the injury (Sykes and Matza 1957). Fourth, the condemnation of the condemners was proposed as the offender shifted the blame out of spite and shifted the blame onto the victim (Sykes and Matza 1957). Fifth, an appeal to a higher loyalty was proposed as the 
offender's friends were counting on him or her, so the dilemma of what to do fell on the shoulders of the offender (Sykes and Matza 1957).

Giddens's (1984) study of adolescent boys found that if there was a potential for being caught, boys would have thought consciously about their behavior as they could justify, excuse, or defend it should they be caught (Teeven and Dryburgh 1999: 78). Dodder (1990: 487) found that neutralization and delinquent behaviors were the strongest paths among Anglos and among males. Boys are more willing to justify and defend their actions to stay out of trouble than girls are.

An example used for this theory concerns gang activity. In a study of 6,000 middle school students conducted by Esbensen, Deschenes, and Winfree (1999: 46), researchers found 623 students (slightly over 1\%) met the restricted definition of being a gang member, with $62 \%$ being male and $38 \%$ being female. Gang members tend to lean toward a "brotherhood" or code that guides them in their daily lives. According to this study, female gang members have had an increase in activity and are not as rare as court record indications.

Mitchell and Dodder (1990: 487) conducted a study comparing sex and ethnicity and their affects on neutralization and delinquency. The study analyzed the relationship between church attendance and association with peer delinquents, their tendency to neutralize, and self-reported delinquent behavior. Mitchell and Dodder (1990: 481) concluded that having more delinquent friends was related to greater neutralization of delinquent acts. When an adolescent makes the choice to engage in a delinquent act, such as drug usage, he or she might remain loyal to his or her peers and give an excuse or justify his or her actions. 
"Which came first, the delinquent act or the belief in justifying it?" (Minor 1984:

996). Minor (1984) did a study using 478 college students; he looked into their behavior, moral evaluations, and willingness to accept excuses for seven relatively innocuous forms of deviance (marijuana and cocaine use, fighting, being drunk and disorderly, cheating on exams, non-martial sex, and shoplifting). He concluded that neutralization could act as a hardening process in the erosion of morals... and excuse acceptance affecting behavior or moral evaluations (Minor 1984: 1000). He found that cocaine use was significant at .01 level when it involved a student's behavior, moral evaluation, and excuse acceptance. To conclude, his study found that when a person's behavior is inappropriate, has a low level of moral evaluation, and the person accepts excuses for his or her behavior, a person is more likely to use cocaine.

\section{Self Control and Delinquency}

When they are children, people tend to be curious to learn new things, what they can and cannot do, what is right and wrong, or whether to challenge their minds or just go about life doing the simplest tasks. Gottfredson and Hirschi (1993) stated, “Individuals with low self-control are impulsive, prefer simple tasks, have a high risk-seeking potential, favor physical (as opposed to mental) activities, are self-centered, and, finally, possess volatile tempers” (Arneklev, Grasmick, and Bursik 1999: 308). These six categories are used to classify someone who has a lower self-control rate as opposed to those with a higher one. Not all the characteristics are warning signs of low self-control; they are just some indicators. If a person falls into any one of the categories every now and then, that does not mean he or she has low self-control; it just shows they like a little excitement in his or her life. However, someone with low self-control tends to learn such 
behaviors through his or her associations with peer groups.

Like Gottfredson and Hirschi, Cowen (1991: 362) defined self-control as having two categories: The rule-oriented self and the impulsive self. Each "self" represents a way in which a person chooses to either engage in a deviant act or to control and stay clear of such acts. The rule-oriented self is defined as "forces in a personality, which attempt to impose regularities and controls on a person's behavior.” In contrast, the impulsive self refers to "the forces that favor spontaneity and unpredictability" (Cowen 1991: 362).

What can cause a person to have low self-control? According to Gottfredson and Hirschi (1990), it comes from inadequate child-rearing experiences that translate into individual differences in low self-control, and it is the lack of such control that produces differential involvement in criminal behaviors (Arneklev, Grasmick, and Burisk 1999: 308). When developing, children need to have a strong social bonds to his or her parents, not to a television or a video game, a computer, or nanny; he or she needs the love from his or her mom and dad. Arneklev, Grasmick and Burisk's 1999 article Evaluating the Dimensionality and Invariance of "Low Self-Control," found that low self-control reflects an invariant criminal predisposition; its forms do not change with the age or context in which they reside (1999: 327).

In conclusion, it seems that a person with low self-control, as opposed to a higher level, are more likely to engage in or commit delinquency: "individuals might be motivated by different psychological constructs and, therefore, be differentially driven toward particular (specialized) crimes” (Arneklev, Grasmick, and Burisk 1999: 311).

\section{Parental Monitoring and Delinquency}


Low parental-monitoring refers to parents being unaware of where their child is, whom they are with, and what he or she is doing (Curtner-Smith and MacKinnon-Lewis 1994: 462). Unfortunately it seems that some parents have lost the idea that "peer and parental influence have been found to be important variables in teenage drug and drinking behavior (Akers, Krohn, Lanza-Kaduce, and Radosevich 1979: 639). Master (1948: 386) stated "one must remember that parents and teachers have the closet relationship with the child during the period when "the foundations of delinquent behavior are usually laid.” A child, who has a strong attachment to his or her parents during the foundations of his or her life, are less likely to get involved with drugs and delinquent friends than those with a weaker attachment.

A previous study done by Dornbusch (1985) found that teenage boys living with only their mother exhibited higher rates of deviant behavior than boys living with only their single-mother and an additional adult or boys living with both biological parents (Curtner-Smith and MacKinnon-Lewis 1994: 462). According to the U.S. Bureau of the Census (1990), 51\% of African American children compared to 16\% of White children under the age of 18 were living with a single mother (Thomas, Farrell, and Barnes 1996: 885). Thomas, Farrell and Barnes (1996: 892) found that White males with single mother homes and a non-resident father, who is not involved in their lives, are far more likely to drink heavily and use illicit drugs than Black males. However, they also found that when the non-resident father stays involved with Black males they also are for more likely to drink heavily and use illicit drugs (1996: 892).

In conclusion, single parent households contain more delinquent boys than households containing more than one influential adult (Curtner-Smith and MacKinnon- 
Lewis 1994). Race and age might play an important role. But altogether race is often a critical variable in many theories of crime, little empirical research has examined competing explanations of the race-delinquency relationship (Matsueda and Heimer 1987: 826).

\section{Peer Delinquency and Association}

"Individual or group behavior is deviant if it falls within a class of behavior for which there is a probability of negative sanctions subsequent to its detection,” (Black and Reiss: 2). Unfortunately, this statement can only be true if and when the person is caught in the act. According to Kraus (1977) "to the boys, peer influence is the most frequent cause of delinquency, with boredom and parental inadequacy of somewhat less importance” (Teevan and Dryburgh 1999: 78). When looking at peer influence and delinquency, a common area is between gang and gang research. What is a gang? According to Thrasher (1927), a gang can be defined by its criteria such as:

“(a) A spontaneous and unplanned origin, (b) intimate face-to-face relations, (c) a sense of organization, solidarity, and morale that is superior to that exhibited by the mob, (d) a tendency to move through space and meet a hostile element, which can precipitate cooperative, planned conflict, a morale-boosting activity in itself, (e) the creation of a shared esprit de corps and a common tradition of 'heritage of memories,' and (f) a propensity for some geographic area or territory, which it will defend through force if necessary," (Esbensen, Winfree, He, and Taylor 2001: 107-108).

Gang membership is one of the leading causes of peer delinquency: "gang members appear to act in a delinquent manner more than non-gang members with delinquent friends, suggesting an additional effect of gang membership over and above the delinquent peer effect” (Weerman and Smeenk 2005: 501). According the to The Office of Juvenile Justice and Delinquency Prevention (OJJDP) (1997), gang memberships in the United States in the mid-1990s ranged from about 660,000 to perhaps 
as many as 1.5 million (Esbesen, Winfree, He, and Taylor 2001: 106). What causes a person to join a gang? “The most plausible explanations relate to the differences in learning and reinforcement of behaviors through the process of socialization” (Deschenese and Esbensen 1999: 67-68). People may join to socialize with other peers with similar ideas and interests and to have a sense of belonging to a particular group of people. Once in the gang, the individual might do what it takes to stay in good standing with the other members: "mechanisms for enhancing conformity with law-breaking adolescents are fear of ridicule, the desire to show loyalty and the desire to maintain status” (Weerman and Sneenk 2005: 502-503).

Growing up in an urban area can place limitations on a child relative to whom they interact. Violence in the inner city prohibits children from playing freely with their friends. During the process of "finding themselves" or socialization, children tend to gravitate toward people such as their family and other friends. The Rochester Youth Development (1988), a study conducted by Bjerregaard and Smith, surveyed 1000 students in seventh and eighth grade. The study based on a total of 729 males and 271 females (males were over-sampled because they are more likely to engage in more serious delinquency) found that "the only variable that was uniquely associated with gang membership for females was school expectations” (Deschenese and Esbensen 1999: 70). The researchers found that lower expectations led to a desire of females to want to join a gang. However, during a reanalysis of the Rochester Youth Development study, “community and environment, as measured by neighborhood disorganization and violence, were most significant risk factors for females then males,” (Deschenese and Esbensen 1999: 70). 
“Since peers are believed to be the major socializing agent during adolescence it is important to empirically assess whether adolescents are typically located to homogenous friendship networks with all delinquent or non-delinquent members” (Haynie 2002: 100). While growing up, most youths tends to socialize with peers who have similar interests and ideas. When constructing a bond with a person or group, the individuals involved might experience the same attitudes, feelings, and behaviors; the longer that the individual is together with the group the stronger that bond becomes. Previous works done by Sutherland (1947), Akers (1973), and Hirschi (1969) have found that "the relationship between delinquent peers and delinquency is reciprocal, the result of selection as well as of influence,” (Weeman and Smeenk 2005: 500).

Peer delinquency and youth association is important in that while growing up, individuals gravitate more toward those who are similar. Once they make those bonds, the longer they are involved with that person or persons, the stronger their bond, and influence becomes on one another. If that person or group has delinquent intentions, then more than likely he or she might engage in delinquent acts as well; however, having lifelong friends may not necessarily lead to delinquent behaviors.

\section{Self Worth}

“Self worth,” refers to how a person feels about him or her self, his or her overall self-evaluation. It is based on virtue being grounded in norms and values concerning personal and interpersonal conduct (Gecas 1982: 5). Kaplan’s $(1975,1980)$ esteemenhancement model argues that adolescents are more likely to rebel against social norms when their participation has experienced self-derogatory (Owens 1994: 396). However, with so much competition going on among youths, how does it affect their view of 
themselves? Even if a person fits into all those categories, it does not mean he or she is satisfied with his or her self. “The self-esteem motive is a manifest in general to distort reality in the service of maintaining a positive self-conception, through selective perceptions, reconstruction of personal history, or the classic ego-defensive mechanisms” (Grecas 1982: 21). An unhappy person has a tendency to seek out other alternatives to his or her behavior, either alone or with a group; these behaviors are outside the conventional order of society, but will provide a more positive experience that will help to raise his or her self esteem (Wells 1978: 194). Parents, teachers, and politicians blame poor school achievement, risky sexual behavior, insolence, psychological and emotional distress, drugs and alcohol abuse, and delinquency on a children’s flagging self-esteem (Owens 1994: 391).

According the self-role theory, persons are constituted by the process of interactively validating a self-identity within ongoing activities, which are themselves shaped by social structure of available or appropriate identities (Wells 1978: 191). Socialization allows a person to identify with other peers and in accordance with the bonding self-praise, along with group praise, helps to boost the self-esteem of the adolescent. Once a person identifies him or her self he or she could start to open up to criticism from others, causing either higher levels of self worth or lower levels. According to Owens (1994: 391), youths with high self-esteem will behave in more socially acceptable ways than those with low self-esteem and will show higher achievement in conventional pursuits and greater socio-emotional well-being. What defines a person as having high self-esteem? First, a person might feel good about him or her self, always positive his or her lives and the decisions he or she 
had made. Second, a person thinks that he or she is doing well in school and always tries his or her best to complete school activities. Finally, a person may think he or she can achieve his or her personal goals.

\section{Conclusion}

Previous research has shown a need to examine the relationship between social bonds and drug usage among juveniles. Other factors such as self-control, parental monitoring, peer delinquency, and self-worth have been shown to have a relationship with adolescent drug abuse problems. In this study, these control variables, along with age, sex, and ethnicity, will be empirically analyzed in order to add to the existing research and literature on the matter of drug use and help gain a better understanding of the relationship between social bond theory and juvenile drug usage.

\section{Methods}

\section{Data}

The data for this study came from the Evaluation of the Gang Resistance Education and Training (G.R.E.A.T.) Program in the United States, 1995-1999 (Esbensen 2002). The G.R.E.A.T. data consisted of five parts; each part tested the effectiveness of the program within the United States. To repeat, four out of the five parts consisted of a cross-sectional analysis of students, law enforcement, educators, and parents. The fifth part was a longitudinal analysis of students to find out about their behaviors and feelings towards gang related activities in their schools. The study at hand will analyze and evaluate Part I of the G.R.E.A.T. data set, a cross-sectional study of students within 11 selected cities. This study will analyze the first part of the G.R.E.A.T. data set, (spring 1995), a cross sectional study between seventh and eight grade students who were 
involved with the G.R.E.A.T. study during the 1993-1994 academic school year. Part I, spring 1995, was chosen for a couple of reasons. First, the students who were involved during the 1993-1994 academic school year and surveyed in 1995 had the same officer training them. Second, the variables in part one contained the information needed to complete the study.

Sample

The sample for the cross-sectional study of the G.R.E.A.T. evaluation consisted of exactly 5,935 eight-grade students from 315 classrooms in 42 different schools. The 42 schools were located within eleven cities: Phoenix, Arizona; Torrance, California; Orlando, Florida; Pocatello, Idaho; Will County, Illinois; Kansas City, Missouri; Omaha, Nebraska; Las Cruces, New Mexico; Philadelphia, Pennsylvania; Providence, Rhode Island; and Milwaukee, Wisconsin. Reasons for sample exclusion included: (1) a number of cities had not implemented the program, (2) not all the sites had processed enough students through the program the prior year for the retrospective data collection planned. The final exclusion; in some sites, police officers had instructed the $7^{\text {th }}$ graders, so there could be no comparison group of students who had not received the G.R.E.A.T. training (Esbensen 1995).

\section{Study Design}

For the analysis of the data set, I used logistic regression (multivariate and binary) to compare and contrast the effects of certain independent variables on juvenile drug usage. Indexes were created to measure elements of social bond (attachment, commitment, involvement, belief), and neutralization, (neutralization of lying, stealing, 
and violence), parental monitoring, self worth, and self-control.

\section{Measures}

The instrument used in the cross-sectional component of the G.R.E.A.T. evaluation was a self-answered questionnaire that were administered in the spring of 1995, following the completion of the course in the 1994 academic school year. Measures that were used for this study were to test social bond theory (Hirschi 1969) and neutralization theory (Sykes and Matza 1957). The variables measured a person's attitude toward attachment, commitment, involvement, and belief as well as, attitudes towards neutralization, parental monitoring, peer delinquency, self worth, and selfcontrol. Also age, sex, and ethnicity were included as control variables.

\section{Independent Variables}

Demographic variables. The demographic variables being examined were sex, age, and race. Analyzing sex discovered that males accounted for $48 \%(n=2830)$ and females accounted for 51.9\% ( $\mathrm{n}=3054)$. For statistical purposes, the variable sex was recoded so that females would equal zero (0) and males would equal one (1). When looking at the age of the respondents, $0.01 \%(n=4)$ were age $11,0.02 \%(n=9)$ were age $12,28.8 \%(n=1686)$ of the respondents were age 13 . Sixty percent $(n=3530)$ of the respondents were age $14,9.8 \%(n=577)$ of the respondents were age $15,0.4 \%(n=25)$ of the respondents were age $16,0.0 \%(n=1)$ of the respondents were age 17 and $0.2 \%(n=9)$ of the respondents were aged 18 or older. Regarding race, it was discovered that $40.3 \%$ ( $\mathrm{n}=2355)$ of the respondents were White, 26.4\% $(\mathrm{n}=1544)$ were Black or African American. Eighteen and a half percent $(\mathrm{n}=1098)$ were Hispanic or Latino, 2.3\% $(\mathrm{n}=134)$ were American Indian or Native American, 5.9\% $(\mathrm{n}=346)$ were Asian or Pacific Islander 
or Oriental, $1.6 \%(n=97)$ were other, and $4.3 \%(n=258)$ of the respondents listed themselves as “mixed.” For statistical purposes, race was recoded into one dummy variable where zero (0) was equal to non-White and one (1) was equal to White.

Social Bond. Four key social bond variables were created to account for a person's social bond; these variables were attachment, involvement, commitment, and belief. Each variable was created using specific questions that were listed in the G.R.E.A.T. data. For instance, attachment was determined by combining all the variables that showed a bond to a parental figure by asking the respondents to indicate how much time they spent with their parents. The following were the statements given to the question asked: (1) “can talk to mother,” (2) “my mother trusts me,” (3) “mother knows who my friends are,” (4) “my mother understands me,” (5) “ask for my mother’s advice,” (6) my mother praises me,” (7) “can talk to father,” (8) “my father trusts me,” (9) “my father knows who my friends are,” (10) “my father understands me,” (11) “I can ask my father for advice,” and (12) “ my father praises me.” These questions were combined to create a total attachment variable with 5202 cases, a mean of 55.8 standard deviation of 14.9 , and an alpha value at .88 .

For involvement, I had to use a variable that showed a lack of involvement in extra-curricular activities. The respondents were asked to answer the question, “The hours spent not doing anything in particular.” For statistical purposes, the variable was recoded in 0-9 equal zero (0) and 10 to 989 was equal to one (1).”

To create a commitment variable, I combined questions that asked the respondents if they agreed or disagreed with the following statements: (1) "I try hard in school,” (2) “my grades are important to me,” and (3) “I finish my homework.” The 
questions were combined to create a total commitment variable containing 5845 cases with a mean value of 11.6, a standard deviation of 2.5 and an alpha value of .63.

Finally, for belief, two variables were combined to create a dummy variable. The respondents were asked if they agreed or disagreed with the following statements: (1) “police are honest.” This questions was used to create a total belief variable containing 5805 cases, a mean of 6.6, and a standard deviation of 1.6.

Neutralization. Three key variables I created to test the theory of neutralization and its affect on juvenile drug usage: are neutralization of lying, stealing, and violence. All three variables were created by asking specific questions in the G.R.E.A.T. evaluation survey. First, I took all the questions that asked students if they agreed or disagreed that it was ok to lie to create neutralization of lying. These were the following questions: (1) “it’s ok to tell a small lie as long as no one gets hurt,” (2) “it’s ok to lie to keep your friends from getting into trouble,” and (3) “it’s ok to lie to keep you from getting into trouble.” These three questions were combined to create a total neutralization of lying variable using 5826 cases, a mean value of 9.3, a standard deviation of 2.9 and an alpha value of .78.

The second index was created to measure neutralization of stealing. The students were asked if they agreed or disagreed that, it was ok to steal. The following survey questions were used to measure neutralization of stealing: (1) "it's ok to steal from the rich who have the money to replace it,” (2) “it’s ok to take little things from stores,” and (3) “it's ok to steal if it is the only way you can get it.” Each variable was then combined to create a total neutralization of stealing variable with 5827 cases, a mean value of 6.6, a standard deviation of 3.2 and an alpha value of .86 . 
Finally, the last neutralization index looked at was violence. The students were asked a sense of questions relative to whether they agreed or disagreed with the idea that it was ok to participate in violent acts. The following three questions were used: (1) “it's ok to get into a fight if you are hit first," (2) "it’s ok to fight if you are protecting your rights,” and (3) “it’s ok if there is a threat of hurting you or your friends.” Those questions were combined to create a total neutralization of violence variable using 5854 cases with a mean of 11.9, a standard deviation of 2.9 and an alpha value of .83 .

Social bond and neutralization are some of the variables that were used to look at drug usage and juveniles, but there were some other control variables that were included as well. For instance, I created a variable called "self worth.” To create the variable, I combined all questions that asked how someone felt about his or her self. The following questions were used: (1) “I'm a useful person,” (2) “I'm a person of worth,” (3) “I do a good job at being a person,” (4) I'm able to do things,” (5) “I feel good about myself,” and (6) "When I do a job, I do it well.” These questions were combined to create a self worth variable using 5748 cases with a mean score of 24.07, a standard deviation of 4.29 and an alpha value of .80 .

Another control variable created was "self control.” To create this variable, I took all the questions that asked students if they agreed or disagreed that it was ok to act spontaneously. The following questions that created the "self control” variable were: (1) "I act on the spur of the moment," (2) "No effort to prepare for the future,” (3) "I do what brings me pleasure now," (4) "I am more concerned with the short run,” (5) "I test myself by engaging in something risky,” (6) “I take risks for fun,” (7) “I find it exciting to possibly get into trouble,” and (8) “excitement is more important than security.” These 
questions were then combined to create a total self control variable using 5597 cases with a mean value of 23.86, a standard deviation of 5384, and an alpha value of .80 .

The next control variable that I created to test the effects on juvenile drug usage was “parental monitoring.” Each student was asked if he or she agreed or disagreed with the idea of letting his or her parents know where he or she were and what he or she were doing. The following questions were then combined to create this variable: (1) "I leave a note when I go out,” (2) “My parents know where I am,” (3) “I know how to contact my parents,” and (4) “My parents know who I am with.” The questions were put into an index with 5843 cases, a mean value of 14.8, a standard deviation of 3.25, and an alpha value of .73.

The final control variable that I created is "peer delinquency.” Each student was asked if they agreed or disagreed with their peer’s delinquent acts. The following questions were used: (1) “My friends skip school,” (2) “My friends lie to adults,” (3) “ My friends destroy property,” (4) “My friends steal less than \$50,” (5) “My friends steal more than \$50,” (6) “My friends go into buildings to steal,” (7) “ my friends steal a car,” (8) “my friends have hit someone,” (9) “my friends have attacked someone with a weapon,” (10) “my friends have committed armed robbery,” (11) “my friends have sold marijuana,” (12) “my friends have sold illegal drugs,” (13) “my friends use tobacco,” (14) “my friends drink alcohol,” (15) “my friends smoke marijuana,” and (16) “my friends use illegal drugs.” Each question was then combined to create a total peer delinquency variable with 5497, cases a mean value of 31.8, a standard deviation of 13.80, and an alpha value of .94 .

\section{Dependent Variable}


The dependent variable in this study is whether adolescents have or have not used drugs. Originally, the variable that was coded as one (1) was equal to no, and two (2) was to equal yes. For the purpose of my study, I recoded the variable so that zero (0) was equal to no and one (1) was now equal to yes.

\section{Interpreting the Variables}

\begin{tabular}{|c|c|c|}
\hline \multicolumn{3}{|c|}{ Table 1. Demographic Variables } \\
\hline Sex & & n \\
\hline & Male & 2830 \\
\hline & Female & 3054 \\
\hline Age & & \\
\hline & 11 & 4 \\
\hline & 12 & 9 \\
\hline & 13 & 1686 \\
\hline & 14 & 3530 \\
\hline & 15 & 577 \\
\hline & 16 & 25 \\
\hline & 17 & 1 \\
\hline & $18 / o l d e r$ & 9 \\
\hline & & \\
\hline & White & 2355 \\
\hline & Black & 1544 \\
\hline & Hispanic & 1098 \\
\hline & Native & 134 \\
\hline & American & \\
\hline & Oriental & 346 \\
\hline & Mixed & 355 \\
\hline
\end{tabular}


Table 2. Table of Indexes

\begin{tabular}{|c|c|c|c|c|c|c|}
\hline Social Control & & $\mathrm{n}$ & mean & SE & Alpha & Range \\
\hline & Attachment & 5202 & 55.8 & 14.9 & 0.88 & $12-84$ \\
\hline & Commitment & 5845 & 11.6 & 2.5 & 0.63 & $3-15$ \\
\hline & Belief & 5205 & 6.6 & 1.6 & n/a & $2-10$ \\
\hline & Involvement & 5173 & 0.25 & 0.43 & $\mathrm{n} / \mathrm{a}$ & $0-1$ \\
\hline Neutralization & & & & & & \\
\hline & Lying & 5826 & 9.3 & 2.9 & 0.78 & $3-15$ \\
\hline & Stealing & 5827 & 6.6 & 3.2 & 0.86 & $3-15$ \\
\hline & Violence & 5854 & 11.9 & 2.9 & 0.83 & $3-15$ \\
\hline $\begin{array}{c}\text { Control } \\
\text { Variables }\end{array}$ & & & & & & \\
\hline & Self Worth & 5748 & 24.07 & 4.29 & 0.80 & $6-30$ \\
\hline & Self Control & 5597 & 23.66 & 5.84 & 0.80 & $8-40$ \\
\hline & $\begin{array}{c}\text { Parental } \\
\text { Monitoring }\end{array}$ & 5843 & 14.8 & 3.25 & 0.73 & $4-20$ \\
\hline & $\begin{array}{c}\text { Peer } \\
\text { Delinquency }\end{array}$ & 5497 & 31.8 & 13.80 & 0.94 & $16-80$ \\
\hline
\end{tabular}

\section{Data Analysis}

Using the Statistical Package for the Social Sciences (SPSS), odds ratio, bivariate logistic regression, and multivariate logistic regression tests were used to analyze the data. The odds ratio test was used to see how the odds would change between the independent variables and juvenile drug usage. Bivariate logistic regression was used to test the independent variables against drug usage. Finally, multivariate logistic regression was used to express the relationship between the social control variables, the neutralization variables, the control variables and juvenile drug usage.

\section{Hypothesis}

Using such analytical techniques, measures, and values, two hypotheses were generated. Each hypothesis is related to the data: 
Hypothesis 1. An adolescent who has a weak social bond with his or her parents is more likely to get involved in drugs, when controlling for sex, age, ethnicity and neutralization of lying, stealing, and violence.

Hypothesis 2. An adolescent's sex influences his or her social bonds and neutralization affects his or her involvement with drug usage when controlling for parental monitoring, self-control, and self worth.

\section{Findings}

Bivariate logistic regression analysis.

Table 3 depicts the use of binary logistic regression to see the relationship between the independent variables and juvenile drug usage. Many of the independent variables are statistically significant to drug usage.

Table 3. Bivariate Logistic Regression to Predict Juvenile Drug Usage

\begin{tabular}{|l|c|c|c|}
\hline & Coefficient & S.E. & Odds Ratio \\
\hline Age & $.356^{* *}$ & .073 & 1.427 \\
\hline Ethnicity & & & \\
Non-White vs. White & $.285^{* *}$ & .098 & 1.330 \\
\hline Sex & .179 & .098 & 1.196 \\
\hline Attachment & $-.049^{* *}$ & .003 & .952 \\
\hline Commitment & $-.341^{* *}$ & .018 & .771 \\
\hline Involvement & $1.312^{* *}$ & .109 & 3.714 \\
\hline Belief & $-2.447^{* *}$ & .040 & .087 \\
\hline Neut. of Lying & $.352^{* *}$ & .020 & 1.422 \\
\hline Neut. of Violence & $.328^{* *}$ & .026 & 1.389 \\
\hline Neut. of Stealing & $.315^{* *}$ & .015 & 1.370 \\
\hline Par. Monitoring & $-.235^{* *}$ & .014 & .790 \\
\hline Peer Delinq. & $.087^{* *}$ & .004 & 1.091 \\
\hline Self-Control & $.195^{* *}$ & .010 & 1.215 \\
\hline Self-Worth & $-.123^{* *}$ & .010 & .885 \\
\hline $\begin{array}{l}* * \text { Significance at the } .01 \text { level } \\
* \text { Significance at the .05 level }\end{array}$ & & & \\
\hline
\end{tabular}


For instance, the variable with the strongest positive relationship is found between “involvement” and drug usage. When a person is not involved in any extracurricular activity, they are 3.714 times more likely to get involved with drugs than those who are involved in the community. Other independent variables that are significantly positively related to drug usage are age $(b=.356)$, race $(b=.285)$, sex $(b=.179)$, neutralization of lying ( $\mathrm{b}=.352)$, neutralization of violence $(\mathrm{b}=.328)$, neutralization of stealing $(\mathrm{b}=.315)$, peer delinquency $(\mathrm{b}=.087)$, and self-control $(\mathrm{b}=.195)$. I also discovered that some of the independent variables are significantly but negatively related to drug usage: attachment $(b=-.049)$, commitment $(b=-.341)$, belief $(b=-.511)$, parental monitoring $(b=-.235)$ and self-worth $(b=-.123)$. Because many of the variables are significant to juvenile drug usage, it is important to include them in the analysis. The demographic variable measuring sex, however, was not significantly related to juvenile drug usage.

Multivariate logistic regression analysis. In order to examine the first hypothesis, adolescent who has a weak social bond with his or her parents are more likely to get involved in drugs, multivariate logistic regression was utilized. Results from the first multivariate logistic regression analysis are listed in Table 4 . The first model in Table 4 represents the relationship between age, sex, and race with juvenile drug usage. The variable with the strongest positive relationship was found between age and drug usage; it shows that for every year a person ages he or she are 1.445 times more likely to get involved with drugs than the previous year. Also significantly positively related to drug usage was ethnicity; it shows that White people are 1.380 more likely to get involved with drugs than non-White people. 


\begin{tabular}{|c|c|c|c|c|c|c|c|c|c|}
\hline & \multicolumn{3}{|c|}{ Model 1} & \multicolumn{3}{|c|}{ Model 2} & \multicolumn{3}{|c|}{ Model 3} \\
\hline & Coefficient & $\begin{array}{l}\text { Odds } \\
\text { Ratio }\end{array}$ & S.E. & Coefficient & $\begin{array}{l}\text { Odds } \\
\text { Ratio }\end{array}$ & S.E. & Coefficient & $\begin{array}{l}\text { Odds } \\
\text { Ratio }\end{array}$ & S.E. \\
\hline Age & $.368 * *$ & 1.445 & .074 & .111 & 1.117 & .133 & -0.15 & .985 & .114 \\
\hline Sex & .114 & 1.121 & .100 & $-.551^{* *}$ & .576 & .138 & $-.606 * *$ & .545 & .153 \\
\hline \multicolumn{10}{|l|}{ Ethnicity } \\
\hline Non-White vs. White & $.322 * *$ & 1.380 & .100 & $.435 * *$ & 1.545 & .133 & $.536 * *$ & 1.710 & .148 \\
\hline Attachment & & & & $-.014 *$ & .987 & .005 & -.004 & .996 & .005 \\
\hline Commitment & & & & $-.130 * *$ & .878 & .028 & $-.078 *$ & .925 & .031 \\
\hline Involvement & & & & $.516^{* *}$ & 1.675 & .134 & $.338 *$ & 1.401 & .146 \\
\hline Belief & & & & $-.135^{*}$ & .874 & .047 & -.010 & .990 & .052 \\
\hline Neut. Of Lying & & & & $.070^{*}$ & 1.072 & .030 & .039 & 1.040 & .033 \\
\hline Neut of Violence & & & & $.117 * *$ & 1.124 & .035 & .039 & 1.040 & .036 \\
\hline Neut. Of Stealing & & & & $.180 * *$ & 1.197 & .024 & $.111^{* *}$ & 1.117 & .026 \\
\hline Parental Monitoring & & & & & & & -.027 & .973 & .024 \\
\hline Peer Delinquency & & & & & & & $.061 * *$ & 1.063 & .006 \\
\hline Self-Control & & & & & & & $.036^{*}$ & 1.036 & .016 \\
\hline Self-Worth & & & & & & & -.031 & .969 & .016 \\
\hline
\end{tabular}

In Model 2, when control variables are entered into the equation the relationships between age, sex, and ethnicity are dramatically changed when the idea of social bond variables and neutralization variables are considered. When social bond variables are incorporated, a person's age has changed from being significant to being not statistically significant; however, the odds ratio decreased from 1.445 to 1.117 . When including social control and neutralization variables, the odds for a person's sex has dramatically changed, going from 1.121 down to .567. Looking at a person’s ethnicity, there was also a change. The odds ratio increased by .165 for White as opposed to non-White.

Examining hypothesis 1. Hypothesis 1 states that an adolescent who has a weak social bond with his or her parents is more like to get involved with drugs when controlling for age, sex, ethnicity, neutralization of lying, stealing, and violence. The 
results of Model 2 show support for hypothesis 1 in that a person with weakened social bonds and high levels of neutralization are more likely to get involved in drug usage than those who have a strong social bond. Controlling for a person's age $(b=.111)$, Model 2 shows that as a person ages in one year increments, are now 1.117 times more likely to use drugs than the previous year. When looking at a person's sex $(b=-.551)$, the odds are $43 \%$ lower for males to get involved with drugs than for females. As for ethnicity ( $b=$ .435), White people are now 1.545 times more likely to use drugs than non-White. When introducing social control variables, "Involvement” and “Commitment” have the strongest statistically significant relationship with delinquency involving drug usage. "Involvement" is significant toward drug usage. A person with low involvement in pro-social activities are $67.5 \%$ times more likely to get involved with drugs than to a person who is actively involved with pro-social activities. Another social bond variable that was statistically significant is "Commitment." When looking at a decrease in increments of one, a teenager who is committed to conventional goals is $12.2 \%$ less likely to get involved with drugs compared to a teenager who has no such commitment. However, when looking at the range of 15 to three, a person with weak commitments to conventional goals (lower end of the range) is $146 \%$ times more likely to get involved with drugs than a person with a strong commitment to conventional goals at the higher end (15) of the range. The other social control variables, "attachment" ( $b=-.014)$ and "belief” ( $\mathrm{b}=$-.135) had negative affects on drug usage. A juvenile with a weak attachment to his or her parents is $1.3 \%$ times more likely to use drugs compared to those with a stronger attachment, but, comparing the range, a person at the lowest level is $93 \%$ more likely to use drugs when there is a weaken attachment unlike a person who is found 
at the highest level of attachment. For "belief," a juvenile who does not believe in social norms and institutions is .874 times more likely to get involved with drugs than a person who believes in conventional social norms and institutions. However, the magnitude of the relationship between social bonds and drug usage was relatively weak: attachment had a coefficient of -.014 , commitment's coefficient was -.130 , and belief's coefficient was -.135.

When looking at neutralization of lying, stealing, and violence with delinquency involving drug usage, stealing had the strongest positive relationship with drug usage. When there is an increase of one increment, an adolescent who believes in neutralizing stealing is 1.197 times more likely to use drugs than someone who does not believe in neutralization of stealing. On the other hand, when comparing the two ends of the range, a person at the highest point in the range who neutralizing stealing is $236 \%$ more likely to use drugs than the person at the lowest point. When looking at neutralization of lying, with an increase of one increment, a juvenile who neutralizes lying is 1.072 times more likely to use drugs compared to someone who does not believe in neutralization of lying. However, when looking at someone who does not believe in neutralization of lying (lower end of the range) compared to someone who strongly believes in neutralization of lying (higher end of the range), a person at the high end of the range is $86.4 \%$ more likely to neutralize lying and use drugs than someone who is at the lower end. Finally, looking at neutralization of violence, with an increase in one increment, an adolescent who engages in a violent act is 1.124 times more likely to get involved with drugs than someone who does not engage in violent acts. Conversely, when looking at someone who does not believe in neutralizing violence (lower end of the range) compared to 
someone who strongly believes in neutralizing violence (higher end of the range), the person at the higher end is $149 \%$ higher than someone at the low end of the range to use drugs. The magnitude of the relationship between neutralization and drug usage was relatively strong: neutralization of lying had a coefficient of .070 , neutralization of violence's coefficient of .117, and neutralization of stealing had a coefficient of .180 .

Examining Hypothesis 2. Hypothesis 2 states that an adolescent's sex influences his or her social bonds and neutralization affects his or her involvement with drug usage when controlling for parental monitoring, self-control, and self worth. In Model 3, the relationships between social bonds and drug usage change when parental monitoring, peer delinquency, self-control, and self-worth are controlled. When controlling for the variables in the final model, ethnicity is still significant but has increased, White persons are $71 \%$ more likely to use drugs than non-White persons compared to 55\% in Model 2. However, sex has now changed to become significant; males are $45 \%$ less likely to get involved with drugs than females are.

Looking at the social control variables, compared to Model 2 "Commitment" and "Involvement" are the two variables that are statistically significant at the .05 level. Unlike Model 2, “Attachment” and "Belief” are no longer statistically significant in the study. With a decrease of one increment, an adolescent with a lower level of commitment to goals and roles in society went from .878 times more likely to get involved with drugs, to .925 times more likely. When comparing someone with a strong commitment to conventional goals (higher end of the range) to someone with a weak commitment to conventional goals (the lower end of the range), a person with a weak commitment is $90 \%$ more likely to use drugs than a person with a high level of 
commitment. "Involvement," shows that a juvenile who spends more time watching television and less time with pro-social activities is now $40 \%$ more likely to use drugs as compared to Model 2 with 67.5\%. There is a weak relationship between social bonds and drug usage; attachment has a coefficient of -.004, commitment's coefficient is -..078, and belief's coefficient is -..101.

When controlling for neutralizations variables, neutralization of stealing is the only statistically significant finding at the .01 level. Compared to Model 2, juveniles who steal and justify their actions are now 1.117 times more likely to use drugs, when comparing a difference of one increment. However, looking at someone who does not believe in neutralizing stealing (lower end of the range) compared to someone who has strong beliefs in neutralizing stealing (higher end of the range), a juvenile (at the higher end of the range) who steals money or property is $140 \%$ more likely to obtain and use drugs.

Also in Model 3, peer delinquency is significant in juvenile delinquency involving drug usage. Going from not-delinquent to delinquent friends, the odds increase by $6.3 \%$ that a person who is involved with all or almost all delinquent friends, who use drugs, will be that much more likely to get involved with drugs than those who do not. The range for peer delinquency is 16 to 84 , with a difference of 64 . Looking at 16 and comparing it to 84, the odds of a person with almost all delinquent friends of getting involved with drugs is $403 \%$. The third model indicates that an adolescent who accepts neutralization of stealing and indicates his or her peers engage in drug usage are more likely to engage in drug usage and stealing than those who do not. 
Model 3 indicates that a child with a low level of parental monitoring will be more likely to get involved with delinquent behavior involving drugs than a child with a high level of parental monitoring. Comparing increments of one, children with a low level of parental monitoring are .973 times more likely to use drugs than those with a high level of parental monitoring. On the other hand, when comparing the higher range of 20 to the lower range of four, a person with low levels of parental monitoring are $43 \%$ more likely to use drugs than someone with a high level of parental monitoring. However, the relationship between parental monitoring and drug usage is weak; it is also not statistically significant.

Results from Model 3 show that a person's self-control level is significantly related to their choice of getting involved with delinquency involving drug usage. When an adolescent goes from a lower level of self-control to a little slightly higher level of self-control, he or she is 1.036 times more likely to get involved with drugs than a person who has a higher level of self-control. Conversely when comparing someone with a high level of self-control (lower end of the range) to someone with no self-control (high end of the range), the person at the higher end is $115 \%$ more likely to get involved with drugs than the person at the lower end. According to the results found in Model 3, a person with a weakened social bond, high level of neutralization, and low rate of self-control is more likely to get involved with drugs than a person with strong bonds, low neutralization levels, and higher rate of self-control. 


\section{Discussion and Conclusion}

The purpose of this study is to examine the affect that social bonds and neutralization have on juvenile drug usage. Results indicate a positive association between a weakened social bond and high levels of neutralization and drug usage. For example, youths who have a weak social bond to society were shown to be more likely to get involved with some type of drug usage. Also, when examining the types of neutralization, that neutralization of stealing was found to be the most statistically significant to juvenile drug usage; however, neutralization of both lying and violence were not significant. Overall, this study shows support for the importance of social bond theory and neutralization theory an as explanation of juvenile drug usage.

Before examining the effects of social bond and neutralization on juvenile drug usage, the data revealed an interesting change among the demographic variables. In Models 2 and 3, age was no longer found to be significant; consequently, a shift in sex occurred showing females becoming more likely to use drugs than males. In each model, the odds of females using illegal drugs decreased when incorporating the other variables. The data showed that ethnicity was statistically significant throughout each model and revealed that Whites were more likely than non-Whites to use illegal drugs. With the incorporation of all the variables, the odds increased in each model for Whites to use illegal drugs. According to the findings from this study, the data show that younger White females compared to younger non-White females are more likely to use drugs when controlling for social bond, neutralization, parental monitoring, peer delinquency, self-control and self worth. 
One of the main goals behind this study was to examine the relationship between social bonds and drug usage while controlling for other variables that are theoretically linked to delinquent behavior. This is important because Hirschi (1969) argued that a person engages in delinquent acts when his or her social bonds to society are weakened. When examining the social bond variables, along with neutralization variables, the results showed a relationship between the social bond variables and juvenile drug usage. In this study, the data indicated that a weakened commitment to conventional goals and an adolescent with low levels of involvement in pro-social activites, that adolescent could be more likely to use an illegal drug than an adolescent who was committed to conventional goals and spent less time watching television. The significant findings were found when comparing the lower and higher ends of the range.

Also, when examining the results of social bond had on juvenile drug usage, the data revealed a negative relationship among attachment and belief. Looking at the changes between each increment of one, there was a statistical significance; however the difference was very little. The data revealed that a juvenile with a low or weakened attachment to conventional, law abiding citizens is1.3\% more likely to use a form of illegal drugs. However, when looking at the differences between two extremes of the range, the lowest point of the range becomes 93\% more likely to engage in the use of illegal drugs. Another social control variable that had a negative effect on juvenile drug usage was belief. The less a person believes in social norms and institutions, the more likely a person is to engage in drug usage. In support of Hirchi’s (1969) Social Bond Theory, the data reveal that a person who has a weak bond to society is more likely to engage in deviant behavior, and for this study, the deviant behavior was illegal drug use. 
The second goal of the study was to examine the relationship between types of neutralization and drug usage. "The acceptance of neutralization might lead to persistent delinquent behaviors,” (Minor 1984). Analyzing neutralization of lying, violence, and stealing, when controlling for age, sex, ethnicity, and social bonds, it was found that neutralization of stealing was statistically significant with an adolescent's use of drugs. However, neutralization of lying and violence were not statistically significant. For example, the research indicates that a person who accepts neutralization of stealing is more likely to obtain and sustain his or her drug habits.

For example, "self-control" was found to have a positive relationship with drug usage and delinquent behavior involving drugs. This supports the findings of Goottfredson and Hirschi (1990) who discovered that individual differences in low self control and the lack of such control that produce differential involvement in delinquent behaviors. The research indicates that a person with high levels of self-control is less likely to get involved with drugs than someone who has lower levels of self-control.

Haynie (2002) argued that an adolescent who reports his or her friends are delinquent tend to report higher levels of delinquency. This research finds evidence that supports the idea that delinquent peers play an important role in a juvenile drug usage. For example, peer delinquency and neutralization of stealing were both found to be positively statistically significant with adolescents using drugs. The research found that adolescents with delinquent friends are more likely to accept neutralization of stealing to justify their use of drugs than those with less delinquent friends.

Another variable found to be associated with delinquency involving drugs in this analysis was ethnicity. For example, ethnicity, commitment, involvement, and peer 
delinquency were all found to significantly relate to drug use among adolescents. The research indicates that White people are more likely than non-White people to get involved with drugs. This finding contradicts the findings of Willie, Gershenovitz, Levine, Glazer and Jones (1960) who found that juvenile delinquency rate in the total non- White population was higher than that rate of the total White population. This analysis indicates that more research is needed in the area of juvenile drug usage and ethnicity.

The final variable that was found to have a positive relationship with drug usage among teenagers was their sex. When only controlling for drug usage, it was found that males were more likely to use drugs than females. However, when controlling for social bonds, neutralization, parental monitoring, peer delinquency, self-control, and self-worth, the roles reversed. Once the control variables were added, the data revealed that females were more likely to get involved with drugs than males.

The significance of this study can be seen in three areas. First, it provides support for the hypothesis that a person with weakened social bonds is associated with delinquency and that youths are likely to get involved with drugs. Second, this study finds evidence that supports Hirschi’s “Social Bond Theory,” (1969) the hypothesis that a person will engage in delinquent behavior when his or her "social bond" with society is weakened. Finally, the study finds evidence to support Sykes and Matza’s “Theory of Neutralization,” (1957) the hypothesis that a person will drift in and out of societal norms and then that person will then justify and rationalize his or her actions.

Results from this study indicate that further research is needed in the area of sex, ethnicity, social bonds, and drug usage. For example, research could study and analyze 
the difference between males and females to see why females are more likely to get involved with drug usage then males. Researchers could analyze the change in ethnicity in using drugs; perceptions are that African-Americans were more likely to use drugs. However, this study has shown that Whites are more involved with drug usage. Another example, research could study into further social bonds, looking at particular groups and sub-cultures to find out what causes them to have weaker bonds with some people and not with others. Further, other studies could examine more in-depth what causes a teenager to want to use drugs or not use drugs.

Also, results from this study indicate that changes in school policies, activities, and punishment need to be augmented. For example, school administrators might implement more classes to discuss drug use and the affects it has not only on the individual but the people around him or her. More school activities should be offered, not just sports, but more clubs, groups, or organizations. Faculty, teachers, and administrators should set aside time to get students more involved with the community. Finally, more harsh punishment might be implemented to students who are caught using drugs. Suspension, is one form of punishment, but would have to include no participation in playing sports for the rest of the year, not attending school sanctioned functions, or being involved in community service.

This study does not provide a complete examination of the relationship between social bonds, types of neutralization, and juvenile drug usage. Unfortunately, this study was done by analyzing only Part I (cross-sectional) of the G.R.E.A.T. data set; therefore delinquency involving drugs may or may not have been in existence prior to the study. However, this study does provide evidence that social bonds and neutralizations are 
important concepts to research and should be examined further to explain delinquent

behavior.

\section{References}

Agnew, Robert. 1991. "A Longitudinal Test of Social Control Theory and Delinquency.” Journal of Research in Crime \& Delinquency 28(2) 126-156.

Akers, Ronald L. 1991. “Addiction: The Troublesome Concept.” Journal of Drug Usage 21(4) 777,17.

Akers, Ronald L., Marvin D. Krohn, Lonn Lanza-Kaduce and Marcia Radosevich. 1979. "Social Learning and Deviant Behavior: A Specific Test of a General Theory." American Sociological Review 44(4) 636-655.

Alston, Reginald J, and Debra Harley. October-December 1995. "Hirschi’s Social Control Theory: A Sociological Perspective on Drug Abuse Among Persons with Disabilities.” Journal of Rehabilitation 61(4) 31-35.

Anderson, Amy. 2002. "Individual and Contextual Influences on Delinquency: The Role of the Single-Parent Family.” Journal of Criminal Justice 35(1) 5-29.

Arneklev, Bruce J., Harold G. Grasmick, and Robert J. Bursik Jr. 1999. "Evaluating the Dimenstionality and Invariance of 'Low Self-Control.'” Journal of Quantitative Criminology 15(3) 307-331.

Barnes, Grace M., Michael P. Farrell. Nov. 1992. "Parental Support and Control as Predictors of Adolescent Drinking, Delinquency, and Related Problems Behaviors.” Journal of Marriage and the Family 54(4) 763-776.

Black, Donald J, and Albert J. Reiss, Jr. "Police Control of Juveniles.” American Sociological Review35 (1) 63-75.

Costello, BJ. 2000. "Techniques of Neutralization and Self-Esteem: A Critical Test of Social Control and Neutralization Theory.” Deviant Behavior 21(4) 307-329.

Cowen, Tyler. Jan 1991. "Self-Constraint Versus Self-Liberation.” Ethics 101(2) 360373.

Creswell, John W. 2003. Research Design: Qualitative, Quantitative, and Mixed Methods Approaches. 2d ed. Thousand Oaks, CA: Sage. 
Deschenes, Elizabeth Piper, and Finn-Aage Esbensen. 1999. "Violence and Gangs: Gender Differences in Perception and Behavior.” Journal of Quantitative Criminology 15(1) 63-96.

Dukes, Richard L., and Judith A. Stein. 2001. "Effects of Assets and Deficits on the Social Control At-Risk Behavior Among Youth." Youth and Society 32(3) 337359.

Esbensen, Finn-Aage. 2002. Evaluation of the Gang Resistance Evaluation and Training (GREAT) Program in the United States, 199501999 [Computer file\}. $2^{\text {nd }}$ ICPSR version. Omaha, NE: University of Nebraska at Omaha [producer], Ann Arbor, MI: Inter-university Consortium for Political and Social Research [distributor], 2003.

Esbensen, Finn-Aage, Michelle Hughes Miller, Terrance J. Taylor, Ni He, and Adrienne Freng. June 1999. "Differential Attrition Rates and Active Parental Consent." Evaluation Review 23(3) 316-335.

Esbensen, Finn-Aage, Elizabeth Piper Deschenes and L. Thomas Winfree. September 1999. "Differences Between Gang Girls and Gang Boys: Results from a Multisite Survey.” Youth and Society 31(1) 27-53.

Esbensen, Finn-Aage, and D. Wayne Osgood. May 1999. “Gang Resistance Education and Training (GREAT): Results from the National Evaluation. Journal of Research in Crime and Delinquency 36(2) 194-225.

Esbensen, Finn-Aage, L. Thomas Winfree Jr., Ni He, and Terrance J. Taylor. January 2001. "Youth Gangs and Definitional Issues: When is a Gang a Gang, and Why Does it Matter?” Crime and Delinquency 47(1) 105-130.

Gecas, Viktor. 1982. “The Self-Concept.” Annual Review of Sociology 8 1-33.

Gibbs, Jack P. 1977. "Social Control, Deterrence, and Perspectives on Social Order.” Social Forces 56(2) 408-423.

Gottfredson, Michael R., and Travis Hirschi. A General Theory of Crime. Stanford University Press. Stanford California. 1990.

Greenberg, David F. 1999. “The Weak Strength of Social Control Theory.” Crime and Deliquency45 (1) 66-81.

Greenberg, David F. 1985. “Age, Crime, and Social Explanation.” The American Journal of Sociology 91(1) 1-21.

Haynie, Dana L. 2002. "Friendship Networks and Delinquency: The Relative Nature of Peer Delinquency.” Journal of Quantitative Criminology 18(2) 99-134. 
Hirschi, Travis. 1969. Causes of Delinquency. Berkley, CA: University of California.

Hogan, H. Wayne and Harsha N. Mookherjee. 1981. “Delinquency and Personal vs. Social Controls.” The Journal of Social Psychology 114 51-55.

Huebner, Angela J., and Sherry C. Betts. 2002. "Exploring the Utility of Social Control Theory for Youth Development.” Youth and Society 34(2) 123-145.

Jensen, Gary and David Brownfield. 1983. "Parents and Drugs: Specifying the Consequences of Attachment.” Criminology 21(4) 543-554.

Johnson, William A, Jr., Richard P. Rettig, Gregory M. Scott, and Stephen M. Garrison. 2004. The Sociology Student Writer's Manual. $4^{\text {th }}$ ed. Upper Saddle River, New Jersey: Prentice Hall.

Katz, Rebecca S. 1999. "Building the Foundation for a Side-by-Side Explanatory Model: a General Theory of Crime, the Age-Graded Life-Course Theory, and Attachment Theory.” Western Criminology Review 1(12) 1-17.

Kierkus, Christopher and Douglass Baer. 2002. "A Social Control Explanation of the Relationship Between Family Structure and Delinquent Behavior.” Canadian Journal of Criminology 425-458.

Marcos, Anastasios C., Stephen J. Bahr, and Richard E. Johnson. 1986. "Test of a Bond/Association Theory of Adolescent Drug Use.” Social Forces 65(1) 135161.

Massey, James L. and Marvin D. Krohn. 1986. “A Longitudinal Examination of an Integrated Social Process Model of Deviant Behavior.” Social Forces 65(1) 106134.

Master, J. M. 1948. “Juvenile Delinquency_A Parent-Teacher Challenge.” Journal of Educational Sociology21 (7) 385-390.

Matsueda, Ross L., and Karen Heimer. 1987. "Race, Family Structure and Delinquency: A Test of Differential Association and Social Control Theories.” American Sociological Review52 (6) 826-840.

McCluskey, Cynthia Perez, Marvin D. Krohn, Alan J. Lizotte, and Monica L. Rodriquez. 2002. "Early Substance Use and School Achievement: An Examination of Latino, White, and African American Youth.” Journal of Drug (3) 921-941.

Meier, Robert F. 1982. "Perspectives on the Concept of Social Control.” Annual Review of Sociology 8 35-55. 
Mitchell, J and R.A Dodder. 1990. "Neutralization and Delinquency: A Comparison by Sex and Ethnicity.” Adolescence 25(98) 487-493.

Owens, Timothy J. June 1994. “Two Dimensions of Self-Esteem: Reciprocal Effects on Positive Self-Worth and Self-Deprecation on Adolescent Problems.” American Sociological Review 59(3) 391-407.

Peterson, Dana and Finn-Aage Esbensen. June 2004. “The Outlook is G.R.E.A.T. What Educators say About School-Based Prevention and the Gang Resistance Education and Training (G.R.E.A.T.) Program.” Evaluation Review 28(3) 218245.

Sheley, Joseph F. 1994. "Drug Activity and Firearms possession and Use by Juveniles.” Journal of Drug Issues24 (3) 363-383.

Shoal, Gavin D., and Peter R. Giancola. 2003. "Negative Affectivity and Drug Use in Adolescent Boys: Moderating and Meadiating Mechanisms.” Journal of Personality and Social Psychology 84 (1) 221-233.

Shover, Neal, Stephen Norland, Jennifer James, and William E. Thorton. 1979. Gender Roles and Delinquency. Social Forces 58(1) 162-175.

Smith-Curtner, Mary Elizabeth and Carol E. MacKinnon-Lewis. Oct. 1994. "Family Process Effects on Adolescent males’ Susceptibility to Antisocial Peer Pressure.” Family Relations 43(4) 462-468.

Sweet, Stephen A. and Karen Grace-Martin.2003. Data Analysis with SPSS: A First Course in Applied Statistics. 2d ed. Boston, MA: Pearson Education.

Sykes, Gresham M., and David Matza. 1957. “Techniques of Neutralization: A Theory of Delinquency.” American Sociological Review22 (6) 664-670.

Teevan, James J. and Heather B. Dryburgh. 2000. "First Person Accounts and Sociological Explanations of Delinquency.” 37(1) 77-93.

Terry-McElrath, Yvonne M., and Duane C. McBride. 2004. "Local Implementation of Drug Policy Access to Treatment Services for Juveniles.” Crime \& Delinquency50 (1) 60-87.

Thaxton Sherod and Robert Agnew. 2004. "The Nonlinear Effects of Parental and Teacher Attachment on Delinquency: Disentangling Strain from Social Control Explanations.” Justice Quarterly 21(4) 763-791.

Weerman, Frank M. and Wilma h. Smeenk. 2005. "Peer Similarity in Delinquency for Different Types of Friends: A Comparison Using Two Measurement Methods.” Criminology 43(2) 499-524. 
Wells, L. Edward. 1978. “Theories of Deviance and the Self-Concept.” Social Psychology41 (3) 189-204.

Wiatrowski, Michael D., David B. Griswold, and Mary K. Roberts. 1981. "Social Control Theory and Delinquency.” American Sociological Review 46(5) 525-541.

Willie, Charles V., Anita Gershnovitz, Myrna Levine, Suchochana Glazer, and Roy J. Jones. 1965. "Race and Delinquency." Phylon 26(3) 240-246.

Winfree L. Thomas, Jr., Terrance Taylor, Ni He, and Finn-Aage Esbensen. April 2006. "Self-Control and Variability Over Time: Multivariate Results Using a 5 -Year, Multisite Panel of Youths.” Crime and Delinquency 52(2) 253-286

Young, Sarah J., Sally Longstaffe, and Milton Tenenbein. 1999. "Inhalant Abuse and the Abuse of Other Drugs.” American Journal of Drug Abuse 25 (2) 371-375. 